\title{
An Overview of Vertical Handoff Decision Algorithm
}

\author{
Jyoti Madaan \\ Research Scholar, CSE \\ Manav Rachna International University, Faridabad
}

\author{
Indu Kashyap \\ Professor, CSE \\ Manav Rachna International University, Faridabad
}

\begin{abstract}
In wireless communications of fourth generation the expectation to assimilate a hypothetically numerous heterogeneous wireless technologies are happened under consideration of a novel step toward worldwide smooth access. As the popularity of mobile wireless networks increases as well the challenges of merging a various number of wireless networks increases. Everyone around the world likes to have the best services through best network [11]. Therefore, the aim of NGWNs is to provide a good quality of services between various access networks [24]. To access different networks, there must be a decision algorithm to decide which is the best network for a user for a specific application. This paper presents an Overview of handoff types, handoff process, the criteria involved in VHD, parameters, Existing work on the vertical handoff with comparison tables, Analysis and Various research issues.
\end{abstract}

\section{Keywords}

Vertical Handoff Decision (VHD), Next Generation Wireless Networks (NGWNs), Horizontal Handoff (HHO), Vertical Handoff (VHO)

\section{INTRODUCTION}

The main feature of today's wireless networking system is Mobility. Mobility can be obtained by a handoff mechanism. In future, the users of wireless technologies will not be bound by subscription of one single network; they can choose one of the available networks depending upon the requirement at that moment. The wireless technology beyond $4 \mathrm{G}$ is known as NGWNs, Which will provide support for heterogeneous access technologies. This has led to the development of mobile devices with multiple network interface terminals. The mobile node can connect to any available network (e.g. GPRS, UMTS, WLAN, WI-MAX, BLUETOOTH etc.) These wireless networks are combined to offer high data rate and best services to the mobile nodes [1]. But for accessing different wireless networks, there is a need for vertical handoff decision[24].

The rest of the paper explains different types of handoff, Criteria involved in vertical handoff (VHD), various process of vertical handoff decision making, various existing algorithms to make vertical handoff decision, various research issues in VHD, Finally, we conclude a comparative analysis of various algorithms. Types of Handoff in 4G networks:

\section{TYPES OF HANDOFF}

Handoffs are extremely important to maximize spectrum utilization because of the cellular architecture employed. Handoff is the process of change of base station while maintaining continuity of service during roaming of a mobile terminal [24]. Handoffs can be classified into four types depending upon its control, direction, decision and Process as shown in figure 1. [2].

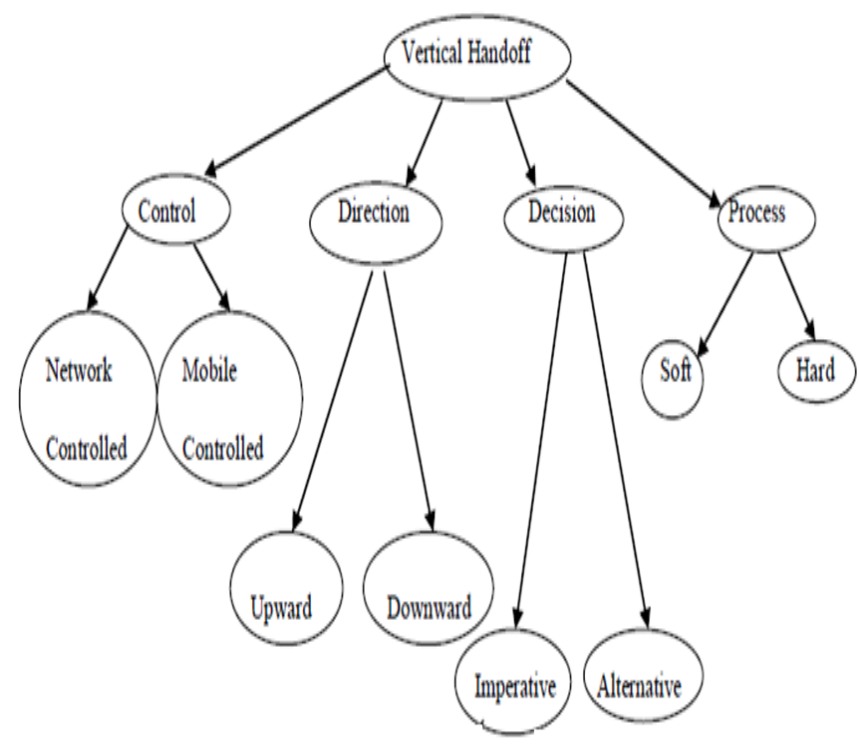

Figure 1: Types of Handoff

\subsection{Handoffs are of Two Types based on the Network Involved:}

2.1.1 Horizontal Handoff:

Handoff between two base stations (BSs) of the same network is called Horizontal Handoff. In Horizontal

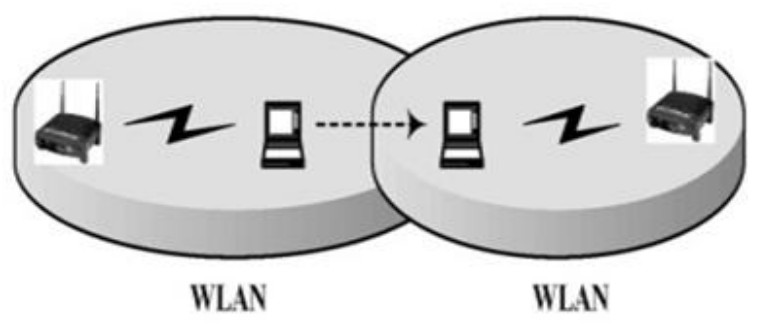

Horizontal handoff: WLAN $\ldots \ldots \ldots$ W... WLAN

Figure 2 Horizontal Handoff

Handoff the mobile node moves from one cell to another of the same network (e.g. Within a UMTS network) to maintain service continuity as shown in figure 2 . It can be further classified into Intersystem Handoff and Intra-system Handoff.

\subsubsection{Intra System Handoff:}

The horizontal handoff between two base stations (BS), under the same BSC is known as Intra system Handoff [24].

\subsubsection{Intersystem Handoff:}

In Intersystem, handoff, handoff occurs between two base stations (BS) of different BSC. It takes place in intra system 
when a mobile terminal departs the regulated realm of one access router and enrolls into the regulated realm of another access router within the same network [24]. Horizontal handoffs are typically required due to the limited coverage of the service access router.

\subsubsection{Vertical Handoff:}

Vertical Handoff occurs between different network technologies such as between an IEEE802.11 access point and a base station of a cellular network as shown in figure 3. [24]. Vertical handoff is again classified into upward, downward, soft, hard, mobile controlled, network controlled, mobile controlled network assisted and network controlled mobile assisted handoff. Vertical handoff can be initiated for providing better Quality of service rather than connectivity. It takes place in intersystem when a mobile terminal moves in between different network technologies for quality of services demanded by the mobile user.

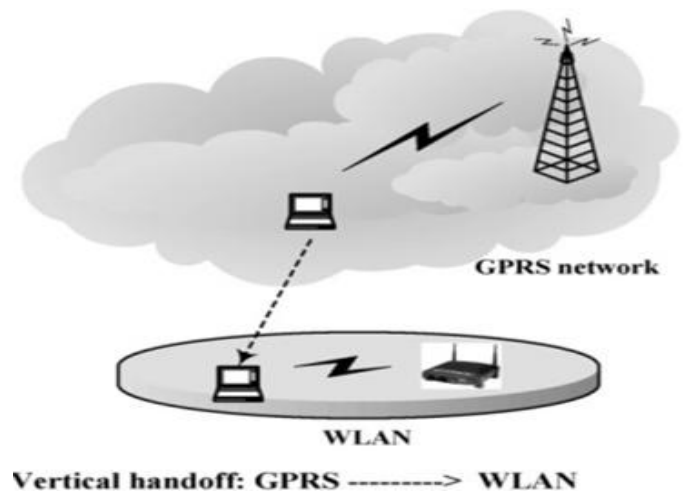

Figure 3: Vertical Handoff

\subsection{Classification based on the Behavior of a Mobile Terminal for Allowing itself for a new Connection. They are Hard Handoff and Smooth Handoff}

\subsubsection{Hard Handoff:}

Hard handoff also called "break before make", involves only one base station at a time. The mobile terminal must break its connection from the current access network before it can connect to a new network.

\subsubsection{Soft Handoff:}

It is also known as "make before break", a mobile station can communicate and connect with more than one access network during the handoff process.

\subsection{Handoff are Classified as Four Types with Respect to 'Who Controls the Handoff Decision}

\subsubsection{Network controlled Handoff (NCHO):}

In this, handoff decision is taken by network only [12]. But, these types of handcuffs cannot be initiated at the right time because they don't have the information about the current circumstances of the mobile terminal. Also, a network cannot be made aware of the characteristics of all other networks. Therefore, it is not suitable for vertical Handovers. A network controlled handoff is suitable for only Horizontal handoff. They are used in the 1st generation cellular system and needs approximately $100-200 \mathrm{~ms}$ time for handoff completion.

\subsubsection{Mobile control handoff (MCHO):}

In this, mobile terminal takes the handoff decision. As mobile terminals have better knowledge of its current circumstances, this type of handoff is a better choice for vertical handover. They need approximately 0.1 second time for the handoff completion process. They are used in Mobile IP networks.

\subsubsection{Network Controlled Mobile Assisted handoff (NCMA):}

In this, mobile terminal assists the network for handoff decision by collecting the primary information required for handoff [12].This type of handoff is used in 2nd and 3rd generation cellular system. They need approximately 1 second for completion of handoff process.

\subsubsection{Mobile Controlled Network assisted handoff (MCNA):}

In this, network assists the mobile terminal for handoff decision. This type of handoff is mostly used in vertical handoff decision process. Because mobile nodes have better knowledge about the network interfaces they are equipped with and the user preference can be taken into consideration.

\subsection{Handoff can be classified as Imperative handoff and Alternative handoffs}

\subsubsection{Imperative handoff:}

They are mandatory handoff and are initiated due to poor network conditions.

\subsubsection{Alternative handoff:}

They are initiated due to user preference rather than an inconvenience.

\section{The Criteria involved in Vertical Handoff Decision:}

The various parameters involved in vertical handoff are very important aspect to achieve continuous \& uninterrupted services [1]. Figure 4 Shows, the most important criteria that must be used In VHD algorithms.

\subsubsection{Received Signal Strength (RSS)}

RSS is a primary decision attribute for vertical handoff because it can be measured easily and it is directly related to the Quality of service. Attribute RSS and the distance between the mobile terminal to the point of attachment is inversely proportional to each other. But RSS is not enough in vertical handoff decision.

\subsubsection{Available Bandwidth}

This criterion is used for identification of network congestion and for the discovery of available resources of communication. This is a most important Criteria for delay sensitive applications. 


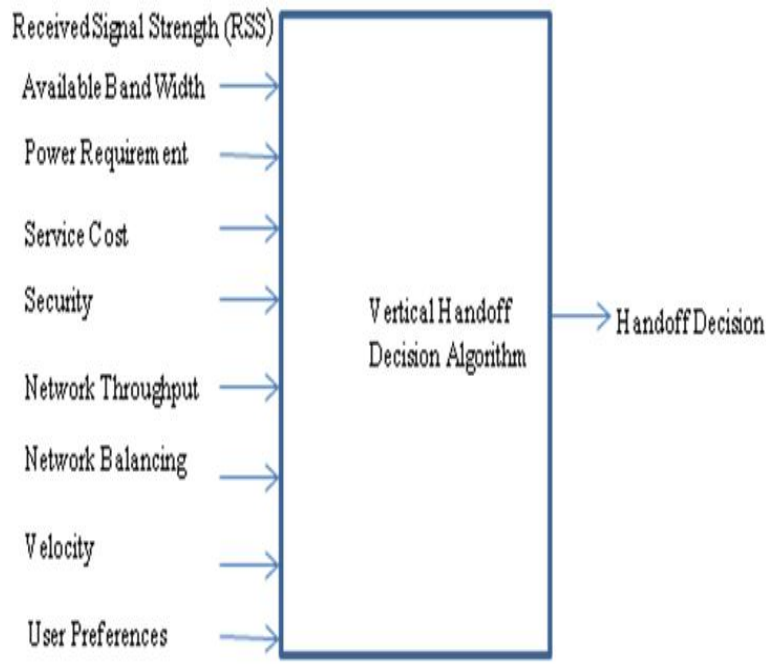

Figure 4: Handoff Decision Criteria

\subsubsection{Power Requirement}

Wireless devices run on battery. Therefore, they must have limited power consumption, if a mobile device has low battery level, then switching from one network to another network with low power requirement (e.g. WLAN to a WWAN) would be a smart decision. This is because, in a WWAN the wireless transmission is unpredictable and the device is inactive for a longer time. Also, the mobile terminals are able to wait between transport activities, because there is no predefined arrival time and transmission of data.

\subsubsection{Security}

The data transmission through a wireless network is less secure as compared wired network. As data is transmitted through the air interface and people do not have control on the accessibility of data. Therefore, to attain a higher level of security \& confidentiality the network should prevent unauthorized access to network resources.

\subsubsection{Network throughput}

Network throughput refers to the average data rate over a specific communication link. It is measured in bits per second. It equals to the TCP window size divided by the round trip of communication data packets.

\subsubsection{Network Balancing}

Network load is an important criteria for effective handoff. Load balancing is required to maintain a uniform traffic among available networks and to avoid overloading of the particular network. The non- uniform distribution of traffic among network reduces the traffic carrying capacity and a quality of communication service. Therefore, it must be paid attention.

\subsubsection{Velocity}

Velocity and the direction of movement of the mobile node should also be considered during the handoff decision. If a mobile node is moving at a very high speed, then hand over the connection to a smaller coverage area network will be discouraged since a handoff back to the original network will occur very shortly.

\subsubsection{User Preferences}

The user preferences and network performance parameter can be used to choose available network. The user preference could depend upon the type of application (real-time, non- real-time), service type (voice, data, video), Quality of service, preferred networks etc.

We have discussed the most important criteria, but other parameters such as network load, packet delay and bit error rate should be taken into account for a good vertical handoff decision (VHD) algorithm.

\section{Vertical Handoff Process}

The handoff process can be divided into 3 phases as shown in figure 5:
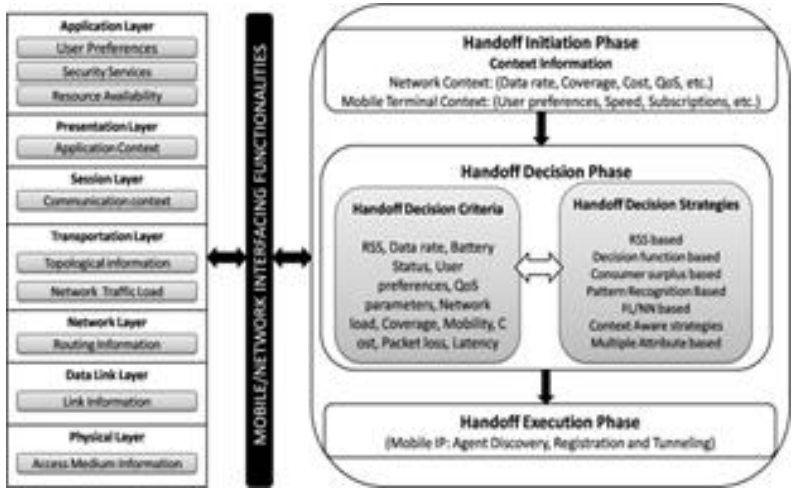

Figure 5: Vertical Handoff Process

\subsubsection{Phase 1 (Handoff Information Gathering)}

This phase is used to collect the information about the network and the mobile node from the upper layers such as a transport layer, Link layer, and application layer. These layers provide the information in terms of received signal strength(RSS), Power requirement, link delay, link cost, user preferences and available bandwidth in order to trigger the handoff [1]. Based on this information, the handoff will be triggered at an appropriate time.

\subsubsection{Phase 2 (Handoff Decision)}

In this phase, the mobile node decides whether to continue with the current network or to switch over to another network with the help of information collected during phase1.

\subsubsection{Phase 3 (Handoff Execution):}

This Phase is used to transfer the user's context information and rerouting the connections to new network after authentication and authorization.

\section{VERTICAL HANDOFF DECISION MAKING ALGORITHMS}

In the literature survey, various vertical handoff decision algorithms are discussed. These decision algorithms can be grouped as follows:

A. Traditional B. User Centric C. Fuzzy Logic and Neural network D. Context Aware E. Functional based F. Multiple Attributes Decision Making

\subsubsection{Traditional Method}

Traditional Methods use RSS with other parameters as decision criteria. The algorithms based on RSS are easy to implement as they do not involve too much complexity. Such a solution is proposed by [K. Pahlavan, et al] [7]. The decision to transfer the mobile node from current network to another mainly depends upon received signal. The major drawback of received signal strength (RSS) algorithm is the generation of large numbers of handoff because received signal strength (RSS) cannot be measured accurately due to path loss and fading of the signal. 


\subsubsection{User Centric Approaches}

The User Centric Approaches considers only user preferences to achieve maximum user satisfaction. The preferences are given in the form of cost and quality of service (QoS). It chooses the best utility function for user satisfaction rather than for applications. An algorithm is proposed by [Calvagna, G.] [3]. In this, the actual transfer rate of each network is calculated by the mobile terminal. It uses the predicted rate and utility function to determine which network is best for a complete transfer of data with maximum utility.

\subsubsection{Fuzzy Logic and Neural Network}

The fuzzy Logic system allows coding in qualitative thinking of human experts Fuzzy Logic (FL) and Neural Network (NN) are two concepts used to choose when and to which network for the implementation of vertical handoff algorithm. The advanced algorithm with improved efficiency and decision criteria can be developed for both real and non-real applications by combining the Fuzzy and Neural networks A vertical handoff solution that uses these two concepts was proposed by [Siddiqui, Farhan, et al.] [22] to produce a very powerful system. In this, algorithm neural network is used as a baseline system. The GA is combined with Fuzzy Logic and Neural Network to select the best network at a given time. In this solution, a string must encode $\mathrm{n} * \mathrm{c}$ real valued parameter in which each coefficient encoded by 8 bits and scaled between [0 1]. After that the GA manipulates the most promising strings in its search for improved solutions.

\subsubsection{Context Aware}

The Context Aware algorithms choose the best network among the available network based on the mobile terminal and network information. They make a balance between user demand and network condition. The decision algorithm based on Context Analytic Hierarchy Process (AHP) is presented by [T. L. Saaty, et al.] [23]. The handoff mechanism is designed for vertical handoff initiation and decision with respect to the changes in context. It is a much more complex algorithm and deals with a much difficult point which has not taken into account earlier.

\subsubsection{Functional Based}

Vertical handoff decisions based on a cost function measures the benefit obtained from switching. The first policy enabled handover strategy is proposed by [H.J. Wang, et al.] [6]. They have used a cost function to select the best available network. This algorithm allows the users to express parameters such as cost, performance and power consumption with their weights. But the cost function presented in this paper is very preliminary and cannot handle complicated configurations.

Other Policy based work is proposed by [K. Radhika et al.] [8], where the Automatic Handover Manager (AHM) provides a solution for selecting the best target network based on automatic computing concepts. This paper describes how to compose the context evaluation function and formulate a policy.

Pramod Goyal \& S. K. Saxena [17] have proposed dynamic decision model for Vertical Handoff Decision algorithm. They have calculated a score function for each candidate network. The network having a highest value of score function is selected as "Best Network" to handoff all the current information to the selected network.

\subsubsection{Multiple Attributes Decision Making}

Multiple attributes decision algorithm chooses an alternative from a set of alternatives which are characterized in terms of their attributes. The various MADM methods are:

Simple Additive weighting method (SAW) [K. Savitha, et al.] [9]: In this the overall score of a candidate network is determined by the weighted sum of all the attribute values.

K. Radhika, et al. [8], had proposed Gray Relational Analysis (GRA) to rank the candidate network and then selects the network with the highest ranking value.

D. Lee, Y. Han and J. Hwang [4], have proposed Quality dependent vertical handover decision algorithm for fourth generation $(4 \mathrm{G})$ Heterogeneous network. They have designed a decision function and cost factor calculation algorithms. The network with the highest quality and lowest cost is selected as the target network for handover.

\section{ANALYSIS}

Table-1 outlines the Name of the algorithm, Method used for decision, Input parameters, Complexity of algorithms, Reliability, Advantages and their Drawbacks. Traditional method considers only few numbers of parameters. Whereas User Centric approach considers the user related parameter and preferences. On the other hand, Multi Attribute decision algorithm considers the maximum number of parameters for decision. Some uses Fuzzy based methods. Which is an intelligent approach. The Context aware decision algorithm considers the user and network context information. This is an efficient method, but with more constraints. The cost function based method uses both static and dynamic parameters for decision making. But there are only few papers which consider call dropping rate and handoff blocking rate as a decision parameter.

\section{RESEARCH ISSUES}

The future Wireless system will be the integration of various wireless access technologies. Therefore, In order to provide seamless, continuous services many challenging issues must be solved:

\subsubsection{Security Issues}

In a wireless transmission, the data are broadcast over the air interface and people do not have control over the transmission boundaries. Therefore, when a sensitive data is transmitted, it should be transferred in a secured manner.

\subsubsection{QoS Issues}

Mobile nodes carrying real time and non-real time traffic should be provided with guaranteed QoS.

\subsubsection{TCP Performance Issues}

When a handoff occurs from a low bandwidth, high data rate network to a high bandwidth, low data rate network then functioning of TCP gets affected. Therefore TCP performance should be considered.

\section{CONCLUSION}

The aim of heterogeneous wireless network is to offer high quality services. Vertical handoff is a most challenging issue for a heterogeneous network to allow seamless roaming for mobile nodes. In this paper, various handoff strategies are discussed. It's clearly concluded that Advanced Analytical strategies are mandatory for an efficient handoff decision algorithm and every efficient handoff decision algorithm should determine the right time for handoff initiation. The various requirements for efficient handoff are low power 
consumption, balanced network load, network security, user preferences, throughput and low handoff latency. But establishing the requirement of a vertical handoff decision for NGWNs is a critical milestone.

\section{REFERENCES:}

[1] Bhuvaneshwari, A., and E. George Dharma Prakash Raj. "An overview of vertical handoff decision making algorithms." International Journal of Computer Network and Information Security (IJCNIS) 4, no. 9 (2012): 55.

[2] Bhuvaneshwari, A., and E. George Dharma Prakash Raj. "A Cross Layer based Vertical Handoff Decision Making Framework." International Journal of Computer Applications 50.19 (2012): 28-32.

[3] Calvagna, G. Di Modica, A user-centric analysis of vertical handovers, in: Proceedings of the Second ACM International Workshop on Wireless Mobile Applications and Services on WLAN Hotspots, 2004, pp. 137-146.

[4] D. Lee, Y. Han and J. Hwang, "QoS-based vertical handoff decision algorithm in heterogeneous systems", in: Proceedings of the IEEE 17th International Symposium on Personal, Indoorand Mobile Radio communications (PIMRC'06),Helsinki, Finland, September 2006, pp. 1-5.

[5] E. Stevens-Navarro, V. Wong, Comparison between vertical handoff decision algorithms for heterogeneous wireless networks, in:Proceedings of IEEE Vehicular Technology Conference (VTC-Spring), vol. 2, 2006, pp. 947-951.

[6] H.J. Wang, R. H. Katz \& J. Giese,(1999) "PolicyEnabled Handoffs across Heterogeneous wireless networks", In proc. Of ACM WMCSA.IEEE Personal Communications 7 (2) (2000) 34-47.

[7] K. Pahlavan, P. Krishnamurthy, A. Hatami, M. Ylianttila, J. Makela, R. Pichna, J. Vallstron, Handoff in hybrid mobile data networks, " Personal Communications, IEEE 7, no. 2 (2000): 34-47.

[8] K. Radhika, Dr. A. Venugopal Reddy, "AHP and Group Decision Making for Access Network Selection in MultiHomed Mobile Terminals", International Journal on Computer Science and Engineering (IJCSE), ISSN : 0975-3397 Vol. 3 No. 10 October 2011.

[9] K. Savitha, C. Chandrasekar, "Grey Relation Analysis for Vertical Handover Decision Schemes in Heterogeneous Wireless Networks", European Journal of Scientific Research, ISSN 1450-216X Vol.54 No.4 (2011), pp.560-568.

[10] K.Ayyappan and P.Dananjayan,(2008)"RSS Measurement forVertical Handoff in Heterogeneous Network", International journal of Theoretical and Applied Information Technology,Vol.4,No.10.

[11] Khattab, Omar, and Omar Alani. "Survey on Media Independent Handover (MIH) Approaches in Heterogeneous Wireless Networks." In Wireless Conference (EW), Proceedings of the 2013 19th European, pp. 1-5. VDE, 2013.

[12] Krichene, Neila, and Noureddine Boudriga. "Securing roaming and vertical handover in fourth generation networks." In Network and System Security, 2009.
NSS'09. Third International Conference on, pp. 225-231. IEEE, 2009.

[13] McNair, Janise, and Fang Zhu. "Vertical handoffs in fourth-generation multi network environments." Wireless Communications, IEEE 11.3 (2004): 8-15.

[14] O. Ormond, G.Muntean and J. Murphy, "Network Selection Strategy in Hetero-geneous Wireless Networks", Proc. of IT\&T 2005: Information Technology and Telecommunications, pp. 175-184, Cork, October 2005.

[15] Patel, Nikhil, and Kiran Parmar. "Quality Dependent Vertical Handover Decision Algorithm for Fourth Generation (4G) Heterogeneous Wireless Networks."IJCEM International Journal of Computational Engineering \& Management 15, no. 2 (2012).

[16] Park, Hyo Soon, et al. "Vertical Hando. Procedure and Algorithm between IEEE802. 11 WLAN and CDMA Cellular Network." Mobile Communications. Springer Berlin Heidelberg, 2003. 103-112.

[17] Pramod Goyal \& S. K. Saxena,(2008)"A Dynamic Decision Model for Vertical Handoffs across Heterogeneous Wireless Networks",677 ? 2008 WASET.ORG, World Academy of Science, Engineering and Technology,Issue 41,pp 676-682.

[18] Radhika and Venugopal Reddy, "Vertical Handoff Decision using Game Theory Approach for Multi-mode Mobile Terminals in Next Generation Wireless Networks", International Journal of Computer Applications, Vol. 36, No.11, pp. 31-37, 2011.

[19] Rehan, Maaz, Muhammad Yousaf, Amir Qayyum, and Shahzad Malik. "A cross-layer user centric vertical handover decision approach based on MIH local triggers." In Wireless and Mobile Networking, pp. 359369. Springer Berlin Heidelberg, 2009.

[20] S.Malathy, G.Sudhasadasivam, K.Murugan and S.Lokesh, "Adaptive Slot Allocation And Bandwidth Sharing For Prioritized Handoff Calls In Mobile Networks", International Journal of Computer Science and Information Security, Vol. 8, No. 1, pp. 52-57, 2010.

[21] Stemm, Mark, and Randy H. Katz. "Vertical handoffs in wireless overlay networks." Mobile Networks and applications 3.4 (1998): 335-350.

[22] Siddiqui, Farhan, Sherali Zeadally, Hesham El-Sayed, and Naveen Chilamkurti. "A dynamic network discovery and selection method for heterogeneous wireless networks." International Journal of Internet Protocol Technology 4, no. 2 (2009): 99-114.

[23] T. L. Saaty, "How to make a decision: The Analytic Hierarchy Process", European Journal of Operational Research, 1990, Vol. 48, pp.9-26.

[24] Verma, Jyoti, and Neeraj Sharma. "Vertical Handoff Decision Model for Next Generation Network Based on Cost Function.", International Journal of Emerging Technology and Advanced Engineering,ISSN 22502459, Volume 3, Issue 12, December 2013 
Table 1: Comparative Analysis Of Various Vertical Algorithms

\begin{tabular}{|c|c|c|c|c|c|c|}
\hline Method & Input Parameters Used & $\begin{array}{l}\text { Handover target } \\
\text { selection area }\end{array}$ & $\begin{array}{l}\text { Complex } \\
\text { ity }\end{array}$ & Reliability & Advantages & Drawbacks \\
\hline $\begin{array}{l}\text { Traditional } \\
\text { Method }\end{array}$ & RSS with Threshold & $\begin{array}{l}\text { The Candidate } \\
\text { network with } \\
\text { the highest } \\
\text { stable RSS }\end{array}$ & Simple & $\begin{array}{l}\text { Reduced reliability because of } \\
\text { fluctuation in RSS }\end{array}$ & $\begin{array}{l}\text { Reduced } \\
\text { number of } \\
\text { handoff } \\
\text { blocking }\end{array}$ & $\begin{array}{l}\text { Low through put } \\
\text {,also the user } \\
\text { preferences are not } \\
\text { considered }\end{array}$ \\
\hline $\begin{array}{l}\text { Cost } \\
\text { Function } \\
\text { Algorithm }\end{array}$ & $\begin{array}{l}\text { Static and Dynamic parameter } \\
\text { such as cost, bandwidth, } \\
\text { power, consumption,RSS }\end{array}$ & $\begin{array}{l}\text { The candidate } \\
\text { network with } \\
\text { the highest } \\
\text { score value }\end{array}$ & Simple & $\begin{array}{l}\text { Reduced reliability because of the } \\
\text { difficulty in accurate measuring of } \\
\text { some parameters }\end{array}$ & $\begin{array}{l}\text { Simplest \& } \\
\text { Fastest } \\
\text { handoff } \\
\text { process, }\end{array}$ & $\begin{array}{l}\text { Ambiguous } \\
\text { handoff decision }\end{array}$ \\
\hline $\begin{array}{l}\text { User } \\
\text { Centric } \\
\text { Approach }\end{array}$ & $\begin{array}{l}\text { User related parameters and } \\
\text { preferences RSS, bandwidth, } \\
\text { power }\end{array}$ & $\begin{array}{l}\text { The candidate } \\
\text { network with } \\
\text { the highest } \\
\text { value of user } \\
\text { satisfaction }\end{array}$ & Complex & $\begin{array}{l}\text { Reduced reliability because it } \\
\text { considers only user } \\
\text { preferences.For a good handoff } \\
\text { decision network network } \\
\text { conditions and constraints should } \\
\text { also be taken into account }\end{array}$ & $\begin{array}{l}\text { Maximize } \\
\text { the user's } \\
\text { level of } \\
\text { satisfaction }\end{array}$ & $\begin{array}{l}\text { Network } \\
\text { parameters are not } \\
\text { considered }\end{array}$ \\
\hline $\begin{array}{l}\text { Context } \\
\text { Aware }\end{array}$ & $\begin{array}{l}\text { User information, user device } \\
\& \text { network context } \\
\text { information }\end{array}$ & $\begin{array}{l}\text { The candidate } \\
\text { network with } \\
\text { the highest } \\
\text { overall } \\
\text { performance }\end{array}$ & Complex & $\begin{array}{l}\text { High reliability but there are more } \\
\text { constraints }\end{array}$ & $\begin{array}{l}\text { Minimum } \\
\text { number of } \\
\text { handoff and } \\
\text { less delay }\end{array}$ & $\begin{array}{l}\text { Multimedia traffic } \\
\text { is not considered }\end{array}$ \\
\hline $\begin{array}{l}\text { Fuzzy \& } \\
\text { Neural } \\
\text { based } \\
\text { Approach }\end{array}$ & $\begin{array}{l}\text { Bandwidth, RSS, jitter, type } \\
\text { of application (real,non } \\
\text { real),delay,error rate }\end{array}$ & $\begin{array}{l}\text { The candidate } \\
\text { network with } \\
\text { the highest } \\
\text { overall } \\
\text { performance }\end{array}$ & $\begin{array}{l}\text { Very } \\
\text { Complex }\end{array}$ & $\begin{array}{l}\text { High reliability because of } \\
\text { intelligent system }\end{array}$ & $\begin{array}{l}\text { Excellent } \\
\text { performance } \\
\text { for delay } \\
\text { sensitive } \\
\text { application } \\
\end{array}$ & $\begin{array}{l}\text { Increases the } \\
\text { complexity }\end{array}$ \\
\hline MADM & $\begin{array}{l}\text { Bandwidth,jitter,security, } \\
\text { cost, loss }\end{array}$ & $\begin{array}{l}\text { The candidate } \\
\text { network with } \\
\text { the highest } \\
\text { overall } \\
\text { performance }\end{array}$ & Complex & $\begin{array}{l}\text { High reliability but there are more } \\
\text { constraints }\end{array}$ & $\begin{array}{l}\text { Reduces } \\
\text { computation } \\
\text { al overhead } \\
\text { and handoff } \\
\text { latency }\end{array}$ & $\begin{array}{l}\text { Increases the } \\
\text { complexity }\end{array}$ \\
\hline
\end{tabular}

AHP-Analytical Hierarchical Process

SAW- Simple Additive Weight

MADM-Multi Attribute Decision Making 